\title{
The Effects of Dietary Nucleotides on Intestinal Blood Flow in Preterm Infants
}

\author{
JANE D. CARVER, MONISHA SASTE, ROBERTO SOSA, JUDY ZARITT, \\ MATTHEW KUCHAN, AND LEWIS A. BARNESS
}

University of South Florida College of Medicine, Department of Pediatrics, Division of Neonatology, Tampa, Florida 33606, U.S.A. [J.D.C., M.S., R.S., J.Z., L.A.B.]; West Coast Neonatology, All Children's Hospital, St. Petersburg, Florida 33701, U.S.A., [R.S.]; Ross Products Division, Abbott Laboratories, Columbus, Ohio 43215, U.S.A. [M.K.]

\begin{abstract}
ABS
Nucleotides (NT) are reported to affect development of the
immune and gastrointestinal systems, and they are currently
added to most term infant formulas. In the present study, dietary
NT effects on superior mesenteric artery blood flow were inves-
tigated. Formula-fed preterm infants were studied once with a 20
kcal/oz. term infant formula containing $80.6 \mathrm{mg} / \mathrm{L}$ of NT $(\mathrm{NT}+)$,
and once with the same formula with no added NT (NT - ) $(n=$
20, gestational age $28.0 \pm 2.2$ wk). A reference group of preterm
infants fed human milk was also studied ( $n=20$, gestational age
$29.0 \pm 1.6$ wk). Superior mesenteric artery blood flow velocities
(BFV) were measured by Doppler ultrasound 15 min before and
30, 60 , and 90 min after the start of the feed. BFV rose in all
infants from baseline to 30 min after feed initiation, and progres-
sively declined thereafter in infants fed NT - or human milk.
However, NT + feedings were associated with a minimal change
\end{abstract}
The splanchnic circulation accounts for $20 \%$ of cardiac output, and at times it may contain one-third of the blood volume $(1,2)$. The inferior portion of the duodenum, the whole of the small bowel, and the right half of the colon are supplied by the SMA. The dependence of intestinal blood flow on a single vessel implies that changes in SMA blood flow patterns may have significant physiologic effects on the bowel $(3,4)$.

The transcutaneous Doppler flow method has been used to evaluate intestinal circulation in infants. Factors including postnatal age, gestational age and birth weight (5-13), intrauterine growth restriction (6, 14-16), birth asphyxia (17), various pharmacologic agents (18-22), and phototherapy (23, 24) are reported to affect splanchnic blood flow patterns in infants.

Received October 25, 2001; accepted May 14, 2002.

Correspondence and reprint requests: Jane Carver, Ph.D., University of South Florida College of Medicine, Department of Pediatrics, Division of Neonatology, 17 Davis Blvd., Suite 200, Tampa, FL 33606, U.S.A.; e-mail: jcarver@hsc.usf.edu

Supported in part by a grant from Ross Products Division, Abbott Laboratories, Columbus, OH, U.S.A.

DOI: 10.1203/01.PDR.0000028457.76706.23 in BFV between 60 and 90 min. As a result, the difference in blood flow velocities between baseline and 90 min was significantly greater with the NT + versus the NT - feedings for the mean, peak systolic, and end diastolic velocities $(p=0.03,0.05$, and 0.03 , respectively). BFV after the NT - and human milk feedings were similar. These data suggest that orally administered NT are associated with effects on the intestinal vasculature.

(Pediatr Res 52: 425-429, 2002)

\section{Abbreviations}

SMA, superior mesenteric artery

BFV, blood flow velocity

NT, nucleotide

$\mathbf{N T}+$, formula with added nucleotide

NT - , formula with no added nucleotides
SMA BFV increases after enteral feeding. Factors that reportedly affect postprandial SMA BFV in infants include feed volume $(5,13)$, interval $(24)$, and composition $(3,8,24-26)$. We (27) and others (28) have reported that increases in SMA $\mathrm{BFV}$ were greater in term infants after a feeding of formula with added NT compared with the same formula with no added NT. NT are naturally occurring substances in human milk, and studies in animals and human infants suggest they influence the development of the immune and gastrointestinal systems (2932). We investigated the effects of feeding NT supplemented formula on SMA BFV in preterm infants.

\section{METHODS}

This protocol was approved by the Institutional Review Board for the Protection of Human Subjects at the University of South Florida. Informed consent was obtained from the parents of each enrolled infant.

Subjects. Inclusion criteria were gestational age $<31$ wk, birth weight $<1800 \mathrm{~g}$, and appropriate for gestational age. Infants with evidence of a patent ductus arteriosus or other cardiac abnormality, evidence of a gastrointestinal abnormal- 
Table 1. NT content of the study formulas $(\mathrm{mg} / \mathrm{L})$

\begin{tabular}{ccc}
\hline & NT - & NT + \\
\hline Total Nucleotides & 7.5 & 80.6 \\
CMP & 3.1 & 38.8 \\
UMP & 3.5 & 16.6 \\
AMP & 0.4 & 12.0 \\
GMP & 0.5 & 13.2 \\
\hline
\end{tabular}

NT present in NT- are inherent to milk ingredients, whereas NT+ was supplemented with approximately $72 \mathrm{mg} / \mathrm{L}$ NT. CMP, cytidine monophosphate; UMP, uridine monophosphate.

ity, ventilatory requirement at the time of study, and phototherapy within $6 \mathrm{~d}$ of being studied were excluded. Infants for whom complete measurements could not be made due to the presence of abdominal gas were excluded. Formula-fed and human milk-fed infants had received more than $90 \%$ of their total enteral intake as formula or human milk, respectively, before the studies.

Feedings. Study feedings for formula-fed infants were a 20 $\mathrm{kcal} / \mathrm{oz}$. ready-to-feed term infant formula with the same composition as Similac with Iron (NT+), or the identical formula with no added NT (NT-). The NT content of the NT+ formula, $80.6 \mathrm{mg} / \mathrm{L}$, was similar to that reported for human milk (33) (Table 1). The formulas were identified by a code, and the investigators were blinded to formula identities until all studies were completed and data were analyzed. Study feedings for human milk-fed infants were their mothers' own, previously frozen, unfortified breast milk.

Study design. Infants were fed at 3-h intervals, and were studied once their enteral intakes were $>200 \mathrm{~mL} / \mathrm{kg} / \mathrm{d}$. Each formula-fed infant served as his or her own control, and was studied using a cross-over design as follows: infants were randomized to be studied with a feeding of NT + on study $\mathrm{d} 1$ and with NT- on study d 2 (group $1, n=10$ ), or with a feeding of NT - on study d 1 and a feeding of NT+ on study $\mathrm{d} 2$ (group $2, n=10$ ). Study d 1 and 2 were consecutive days. Human-fed infants were studied with a single feeding of breast milk $(n=20)$.

Study feedings were given at the time of a regularly scheduled feeding between 1200 and $1500 \mathrm{~h}, 2 \mathrm{~h}$ and $45 \mathrm{~min}$ after the previous feeding was started. All study feedings were administered at $30 \mathrm{~mL} / \mathrm{kg}$, and were delivered by gravity via a nasogastric tube.

Ultrasound measurements. An Interspec Apogee CX annular phased color system with a 7.5-MHz Doppler probe (ATL,
Inc., Bothell, WA, U.S.A.) was used to measure time-averaged mean, peak systolic, and end diastolic SMA BFV 15 min before the start of the study feed (baseline), and 30, 60, and 90 min later. For imaging, the transducer was placed on the mid abdomen above the umbilicus in the sagittal plane. Color flow mapping was used to identify the SMA where it originated from the aorta. The sample volume of the pulsed Doppler was placed a few millimeters distal to the origin of SMA, using an angle correction of $25^{\circ}$. Blood pressure, heart rate, and respiratory rate were recorded at baseline, and the hematocrit was noted. All Doppler studies were performed by one of two ultrasound technicians, however, one technician performed all measurements on a given day.

Statistical analyses. A cross-over statistical design was used to compare diet effects on SMA BFV measurements between group 1 and group 2 infants as follows: the change in velocity from baseline to 30,60 , and 90 min was calculated for study d 1 and 2 . The study $d 1$ changes in velocity were subtracted from the study d 2 changes in velocity; these calculated differences were compared between group 1 and group 2 using a $t$ test.

Comparisons between the combined formula-fed groups and the reference human milk-fed group for baseline BFV and changes in BFV after feedings were analyzed using a threeway ANOVA.

\section{RESULTS}

Birth weight, gestational age, day of life at the time of study, gestation-corrected age, and weight at the time of the study were similar between groups 1 and 2 (Table 2). Postnatal age at the time of the studies was lower for the reference group of human milk-fed infants, reflecting better feed tolerance and more liberal advancement of enteral feedings for human milkfed infants. Between study groups there were no differences in blood pressure, heart rate, respiratory rate, hematocrit, or time required to deliver the study feeding volume via the nasogastric tube.

There were no significant differences in baseline BFV between groups 1 and 2 on study $\mathrm{d} 1$ and 2 . The cross-over statistical analysis revealed that the difference in BFV between baseline and 90 min was significantly greater with the $\mathrm{NT}+$ versus the NT - feedings for the mean, peak systolic, and end diastolic velocities ( $p=0.03,0.05,0.03$, respectively, Table 3 ).

Table 2. Characteristics of study infants

\begin{tabular}{|c|c|c|c|}
\hline & \multicolumn{2}{|c|}{ Formula fed } & \multirow{2}{*}{$\begin{array}{c}\begin{array}{c}\text { Human } \\
\text { milk fed }\end{array} \\
\text { Reference } \\
(n=20)\end{array}$} \\
\hline & $\begin{array}{c}\text { Group 1: } \\
\mathrm{NT}+\Rightarrow \mathrm{NT}- \\
(n=10)\end{array}$ & $\begin{array}{c}\text { Group 2: } \\
\mathrm{NT}-\Rightarrow \mathrm{NT}+ \\
(n=10)\end{array}$ & \\
\hline Birth weight $(\mathrm{kg})$ & $1.2 \pm 0.4$ & $1.0 \pm 0.4$ & $1.3 \pm 0.26$ \\
\hline Gestational age (wk) & $28.6 \pm 2.2$ & $27.4 \pm 2.1$ & $29.0 \pm 1.6$ \\
\hline Postnatal age (d) at time of study & $41.0 \pm 25.3$ & $43.5 \pm 20.8$ & $26.7 \pm 17.1$ \\
\hline
\end{tabular}

There were no significant differences between group 1 and 2 infants. Data are expressed as the mean \pm SD. 
Table 3. Results of cross-over statistical analysis

\begin{tabular}{|c|c|c|c|c|c|c|c|c|}
\hline & \multirow[b]{2}{*}{$\begin{array}{l}\text { Human milk } \\
\qquad(n=10)\end{array}$} & \multicolumn{3}{|c|}{ Group 1: NT $+\Rightarrow \mathrm{NT}-(n=10)$} & \multicolumn{3}{|c|}{ Group 2: NT $-\Rightarrow \mathrm{NT}+(n=10)$} & \multirow[b]{2}{*}{$\begin{array}{c}p \\
\mathrm{X} v s \mathrm{Y}\end{array}$} \\
\hline & & $\begin{array}{l}\text { Day } 1 \\
\text { NT }+\end{array}$ & $\begin{array}{l}\text { Day } 2 \\
\text { NT- }\end{array}$ & $\begin{array}{c}\text { Day } 1-\text { Day } 2 \\
\text { (X) }\end{array}$ & $\begin{array}{l}\text { Day } 1 \\
\text { NT- }\end{array}$ & $\begin{array}{l}\text { Day } 2 \\
\text { NT }+\end{array}$ & $\begin{array}{c}\text { Day 1-Day } 2 \\
\text { (Y) }\end{array}$ & \\
\hline \multicolumn{9}{|l|}{ Mean } \\
\hline-15 to $30 \mathrm{~min}$ & $18.2 \pm 2.9$ & $21.3 \pm 3.5$ & $21.2 \pm 3.4$ & $0.1 \pm 4.3$ & $17.4 \pm 6.7$ & $27.3 \pm 7.1$ & $-9.9 \pm 4.5$ & 0.12 \\
\hline-15 to $60 \mathrm{~min}$ & $12.1 \pm 2.3$ & $14.4 \pm 3.0$ & $10.8 \pm 5.3$ & $3.6 \pm 5.9$ & $17.2 \pm 6.6$ & $14.9 \pm 3.4$ & $2.3 \pm 6.2$ & 0.89 \\
\hline-15 to $90 \mathrm{~min}$ & $4.8 \pm 1.8$ & $15.1 \pm 6.0$ & $1.2 \pm 3.9$ & $13.9 \pm 8.6$ & $8.4 \pm 4.6$ & $16.1 \pm 4.5$ & $-7.7 \pm 2.7$ & 0.03 \\
\hline-15 to $60 \mathrm{~min}$ & $26.1 \pm 5.2$ & $33.7 \pm 6.4$ & $25.9 \pm 10.4$ & $7.8 \pm 11.7$ & $30.4 \pm 13.0$ & $42.5 \pm 7.2$ & $-12.1 \pm 10.8$ & 0.23 \\
\hline-15 to $90 \mathrm{~min}$ & $16.5 \pm 5.0$ & $40.1 \pm 10.0$ & $14.2 \pm 8.6$ & $25.9 \pm 20.6$ & $13.3 \pm 7.2$ & $33.1 \pm 7.2$ & $-19.8 \pm 9.1$ & 0.05 \\
\hline \multicolumn{9}{|l|}{ End diastolic } \\
\hline-15 to $30 \mathrm{~min}$ & $5.8 \pm 1.4$ & $6.8 \pm 2.1$ & $3.8 \pm 1.6$ & $3.0 \pm 2.8$ & $7.5 \pm 2.4$ & $6.2 \pm 1.8$ & $1.3 \pm 3.0$ & 0.69 \\
\hline-15 to $60 \mathrm{~min}$ & $3.6 \pm 1.3$ & $1.9 \pm 1.6$ & $0.9 \pm 2.0$ & $1.9 \pm 2.7$ & $3.9 \pm 1.7$ & $2.9 \pm 1.7$ & $1.0 \pm 2.3$ & 0.80 \\
\hline-15 to $90 \mathrm{~min}$ & $1.0 \pm 0.9$ & $2.3 \pm 1.9$ & $-2.1 \pm 1.5$ & $4.4 \pm 2.4$ & $0.6 \pm 1.6$ & $3.7 \pm 2.0$ & $-3.1 \pm 2.2$ & 0.03 \\
\hline
\end{tabular}

Group 1 infants received NT + on $\mathrm{d} 1$, and NT - on d 2. Group 2 infants received NT - on $\mathrm{d} 1$ and NT + on $\mathrm{d} 2$. The change in velocity ( $\mathrm{cm} / \mathrm{s})$ for mean, peak systolic, and end diastolic velocities were measured from baseline $(-15 \mathrm{~min})$ to 30,60 , and $90 \mathrm{~min}$ after the start of a feed. The $\mathrm{d} 1 \mathrm{change}$ in velocity was subtracted from the $\mathrm{d} 2$ change in velocity for both groups ( $\mathrm{x}$ and y for groups 1 and 2 , respectively). A $t$ test was used to measure the difference between $\mathrm{x}$ and $\mathrm{y}$. Values for the reference group of infants fed human milk are also provided. Data are expressed as the mean $\pm \mathrm{SEM}$.

Figure 1 represents mean values after feedings with NT+, NT-, and human milk. The highest postprandial BFV for all infants was at $30 \mathrm{~min}$. BFV declined from 30 to 90 min after feedings of NT - or human milk. However, after feedings of $\mathrm{NT}+$ there was minimal change in BFV from 60 to $90 \mathrm{~min}$. The three-way ANOVA revealed no significant differences among the human milk, NT-, or NT+ groups in baseline BFV or changes in BFV to 30 and $60 \mathrm{~min}$. However, the change in BFV to $90 \mathrm{~min}$ was significantly greater after a feeding of $\mathrm{NT}+$ compared with NT - and human milk for the mean $(p=$ $0.015)$ and peak systolic $(p=0.033)$ velocities (data not shown).

Postprandial vascular resistance did not decrease among the three diet groups, which may be due to a lower than optimum sampling volume, and/or a high degree of variability in end diastolic velocities relative to peak systolic velocities.

\section{DISCUSSION}

Intestinal blood flow is regulated by intrinsic and extrinsic mechanisms as well as circulating vasoactive substances $(1,2$, 34). The gastrointestinal tract is the source of a number of neurotransmitters, peptides, and autacoids, and its vascular supply is richly innervated by sympathetic and parasympathetic nerves (2). The mechanisms that regulate postprandial splanchnic vascular responses in infants, particularly those born prematurely, are unclear. Larger feed volumes (5) and longer intervals between feeds (25) are reported to result in higher relative postprandial SMA BFV, whereas smaller amplitude and longer latency in SMA BFV responses are reported after a feed with human milk versus formula $(8,25)$. In the present study, SMA BFV rose in all infants from baseline to 30 min after feed initiation, and began to decline thereafter. However, NT + feedings were associated with a sustained increase in postprandial BFV to 90 min after feed initiation. These results are in agreement with studies in term infants (27, 28) demonstrating higher postprandial SMA BFV 90 min after a feeding with formula containing added NT compared with formula with no added NT or human milk.
The clinical significance of a sustained increase in postprandial SMA BFV is unknown. Fang et al. (35) reported a positive correlation between feed tolerance in preterm infants and postprandial SMA BFV 60 min after a feed, suggesting that higher postprandial BFV may be associated with a beneficial physiologic response. In the present study, postprandial BFV were higher after NT + feedings. However, responses after NT - feedings were similar to those after human milk feedings, which are associated with better feed tolerance and clinical outcomes. The divergent SMA BFV response between infants fed human milk and those fed NT+ may relate to differences in NT composition; about $50 \%$ of the NT in human milk are present as RNA, NT+ formula was supplemented with the monophosphate form only (33). However, this is speculative given the numerous compositional differences between formulas and human milk.

The higher SMA BFV measured after NT + feedings may reflect dilation of the intestinal vascular bed. AMP, one of the NT added to the NT+ formula, is hydrolyzed to adenosine within the intestinal lumen (36). Adenosine, a potent vasodilator, plays a role in the regulation of postprandial and reactive hyperemia (37-40). Studies in animals have demonstrated that infusion of adenosine into the arterial supply of the small intestine increases blood flow to the intestinal wall $(37,38$, 41-43) and mucosal layer (44), particularly in younger animals $(45,46)$. In addition, luminal infusion of a NT mixture containing AMP was associated with intestinal hyperemia in newborn swine (46). The results of the present study further suggest that exogenous nucleotides can affect intestinal blood flow. However, in the present study and that of Özkan et al. (28), the most significant difference in BFV between formula feedings with and without NT was seen 90 min after initiation of the feed. Although the metabolic fate of formula NT is unknown, they are probably rapidly degraded within the intestinal lumen. Investigations in animals suggest that nucleosides are the primary form absorbed (47-49), and that over $90 \%$ of nucleosides, and purine and pyrimidine bases are absorbed into the enterocyte $(50,51)$. Once absorbed, most of the nucleosides 

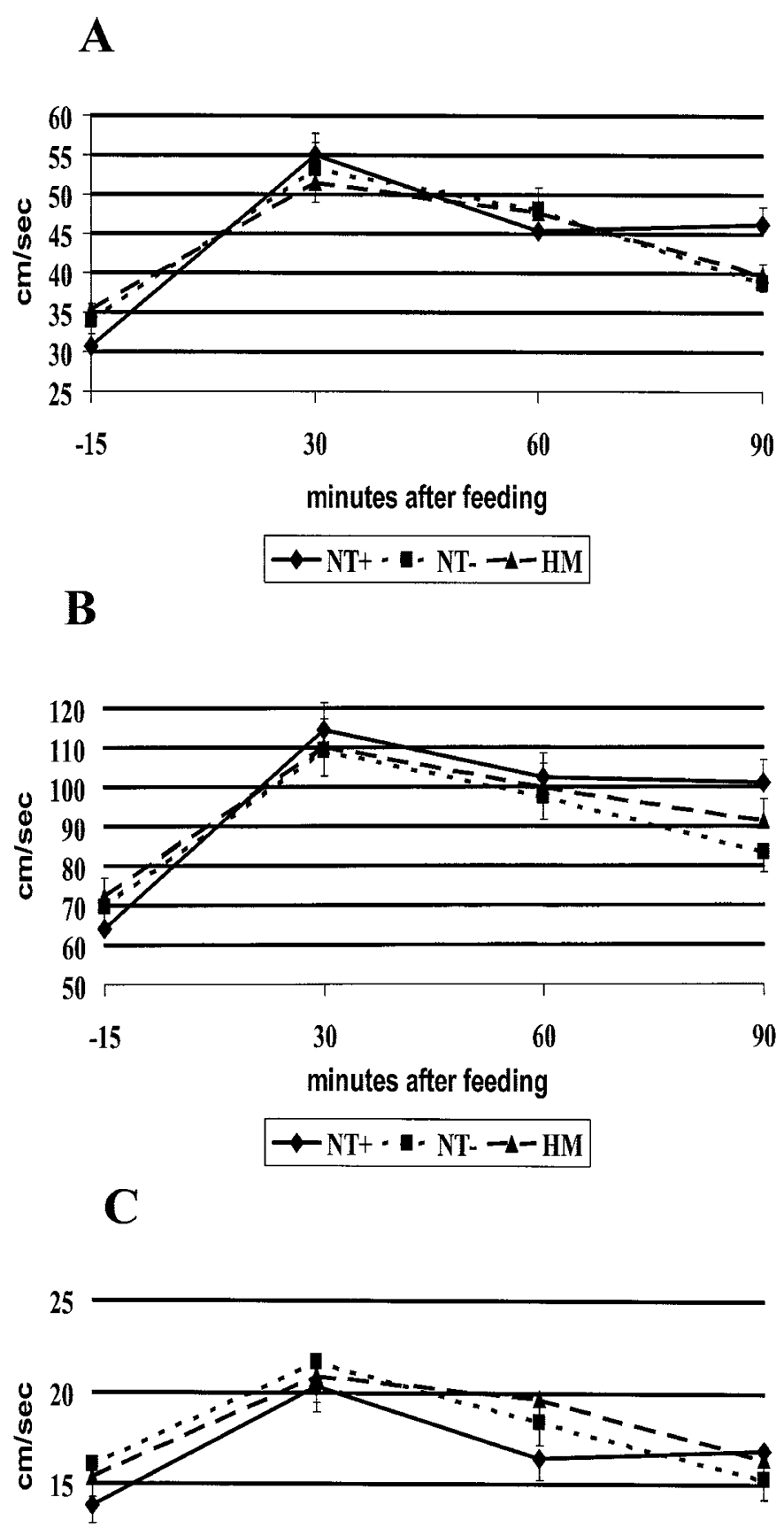

10 $-15$ 30 60

90

minutes after feeding

$\neg \mathrm{NT}+\cdot \mathbf{n T}-\mathrm{NT}-\mathrm{HM}$

Figure 1. Mean velocity $(A)$, peak systolic velocity $(B)$, and end diastolic $(C)$ velocities of blood flow in the superior mesenteric artery of preterm infants 15 min before and 30,60, and 90 min after a feeding of NT + or NT - formula, or with the infant's own mother's milk $(H M)$.

and bases are rapidly degraded, and catabolic products are excreted in the urine and intestines $(48,50,52)$. Thus, although the mechanism by which dietary NT affect splanchnic blood flow is not clarified, this study confirms previous findings of higher postprandial BFV in infants fed NT-supplemented formula $(27,28)$.

NT are presently added to most formulas for term infants. Studies in human infants and in animals suggest that dietary NT enhance development of the gastrointestinal and immune systems (29-32), however, the mechanism of action remains unknown. Our data and those of Özkan et al. (28) suggest that orally administered NT are associated with effects on the intestinal vasculature.

Acknowledgments. The authors thank Kristin Downey and Lisa Wertz for their technical assistance.

\section{REFERENCES}

1. Jacobson ED 1991 The splanchnic circulation. In: Johnson LR (ed) Gastrointestinal Physiology, 4th Ed. Mosby-Year Book, St. Louis, pp 142-161

2. Mathias CJ 1997 Pharmacological manipulation of human gastrointestinal blood flow. Fundam Clin Pharmacol 11:29-34

3. Leidig E 1989 Pulsed Doppler ultrasound blood flow measurements in the superior mesenteric artery of the newborn. Pediatr Radiol 19:169-172

4. Crissinger KD, Granger DN 1991 Gastrointestinal blood flow. In: Yamada T (ed) Textbook of Gastroenterology. Lippincott, Philadelphia, pp 447-475

5. Leidig E 1989 Doppler analysis of superior mesenteric artery blood flow in preterm infants. Arch Dis Child 64:476-480

6. Van Bel F, Van Zwieten PHT, Guit GL, Schipper J 1990 Superior mesenteric artery blood flow velocity and estimated volume flow: duplex Doppler US study of preterm and term neonates. Radiology 174:165-169

7. Coombs RC, Morgan MEI, Durbin GM, Booth IW, McNeish AS 1992 Abnormal gut blood flow velocities in neonates at risk of necrotising enterocolitis. J Pediatr Gastroenterol Nutr 15:13-19

8. Coombs RC, Morgan MEI, Durbin GM, Booth W, McNeish AS 1992 Doppler assessment of human neonatal gut blood flow velocities: postnatal adaptation and response to feeds. J Pediatr Gastroenterol Nutr 15:6-12

9. Agata Y, Hiraishi S, Misawa H, Hirota H, Nowatari M, Hiura K, Fujino N, Oguchi K, Horiguchi Y 1994 Regional blood flow distribution and left ventricular output during early neonatal life: a quantitative ultrasonographic assessment. Pediatr Res 36:805-811

10. Martinussen M, Brubakk AM, Linker DT, Vik T, Yao AC 1994 Mesenteric blood flow velocity and its relation to circulatory adaptation during the first week of life in healthy term infants. Pediatr Res 36:334-339

11. Martinussen M, Brubakk AM, Vik T, Yao AC 1996 Mesenteric blood flow velocity and its relation to transitional circulatory adaptation in appropriate for gestational age preterm infants. Pediatr Res 39:275-280

12. Yanowitz TD, Yao AC, Pettigrew KD, Werner JC, Oh W, Stonestreet BS 1999 Postnatal hemodynamic changes in very-low-birthweight infants. J Appl Physiol 87:370-380

13. Maruyama K, Koizumi T, Tomomasa T, Morikawa A 1999 Intestinal blood flow velocity in uncomplicated preterm infants during the early neonatal period. Pediatr Radiol 29:472-477

14. Mari G, Abuhamad AZ, Uerpairojkit B, Martinez E, Copel JA 1995 Blood flow velocity waveforms of the abdominal arteries in appropriate- and small-forgestational age fetuses. Ultrasound Obstet Gynecol 6:15-18

15. Martinussen M, Brubakk AM, Vik T, Yao AC 1997 Relationship between intrauterine growth retardation and early postnatal superior mesenteric artery blood flow velocity. Biol Neonate 71:22-30

16. Maruyama K, Koizumi T 2001 Superior mesenteric artery blood flow velocity in small for gestational age infants of very low birth weight during the early neonatal period. J Perintal Med 29:64-70

17. Akinbi H, Abbasi S, Hilpert PL, Bhutani VK 1994 Gastrointestinal and renal blood flow velocity profile in neonates with birth asphyxia. J Pediatr 125:625-627

18. Coombs RC, Morgan ME, Durbin GM, Boothy IW, McNeish AS 1990 Gut blood flow velocities in the newborn: effects of a patent ductus arteriosus and parenteral indomethacin. Arch Dis Child 65:1067-1071

19. Hentschel R, Hensel D, Brune T, Rabe H, Jorch G 1995 Impact on blood pressure and intestinal perfusion of dobutamine or dopamine in hypotensive preterm infants. Biol Neonate 68:318-324

20. Seri I, Abbasi SA, Wood DC, Gerdes JS 1998 Regional hemodynamic effects of dopamine in the sick preterm neonate. J Pediatr 133:728-734

21. Pezzati M, Vangi V, Biagiotti R, Bertini G, Cianciulli D, Rubaltelli FF 1999 Effects of indomethacin and ibuprofen on mesenteric and renal blood flow in preterm infants with patent ductus arteriosus. J Pediatr 135:733-738

22. Lane AJP, Coombs RC, Evans DH, Levin RJ 1999 Effect of caffeine on neonatal splanchnic blood flow. Arch Dis Child Fetal Neonatal Ed 80:F128-F129

23. Yao AC, Martinussen M, Johansen OJ, Brubakk AM 1994 Phototherapy-associated changes in mesenteric blood flow response to feeding in term neonates. J Pediatr 124:309-312

24. Pezzati M, Biagiotti R, Vangi V, Lombardi E, Wiechmann L, Rubaltelli FF 2000 Changes in mesenteric blood flow response to feeding: conventional versus fiber-optic phototherapy. Pediatrics 105:350-353 
25. Lane AJP, Coombs RC, Evans DH, Levin RJ 1998 Effect of feed interval and feed type on splanchnic haemodynamics. Arch Dis Child Fetal Neonatal Ed 79:F49-F53

26. Hsu CH, Lee HC, Huang FY 1994 Duplex ultrasonographic assessment of gut blood flow velocity: effect of meal composition in normal full-term newborns after first feed. J Ultrasound Med 13:15-18

27. Carver JD, Sosa R, Zaritt JH, Siktberg MR, Meyer L 2000 Dietary nucleotide effects on superior mesenteric artery blood flow in term infants. Pediatr Res 47:284A(abstr)

28. Özkan H, Ören H, Erdag N, Cevik N 1994 Breast milk versus infant formulas: effects on intestinal blood flow in neonates. Indian J Pediatr 61:703-709

29. Walker WA 1996 Exogenous nucleotides and gastrointestinal immunity. Transplant Proc 28:2438-2441

30. Pickering LK, Granoff DM, Erickson JR, Masor ML, Cordle CT, Schaller JP, Winship TR, Paule CL, Hilty MD 1998 Modulation of the immune system by human milk and infant formula containing nucleotides. Pediatrics 101:242-249

31. Carver JD 1999 Dietary nucleotides: effects on the immune and gastrointestinal systems. Acta Pediatr Suppl 430:1-6

32. Grimble GK, Westwood OM 2001 Nucleotides as immunomodulators in clinical nutrition. Curr Opin Clin Nutr Metab Care 4:57-64

33. Leach JL, Baxter JH, Molitor BE, Ramstack MB, Masor ML 1995 Total potentially available nucleosides of human milk by state of lactation. Am J Clin Nutr 61:1224-1230

34. Hansen MB, Dresner LS, Wait RB 1998 Profile of neurohumoral agents on mesenteric and intestinal blood flow in health and disease. Physiol Res 47:307-327

35. Fang S, Kempley ST, Gamsu HR 2001 Predition of early tolerance to enteral feeding in preterm infants by measurement of superior mesenteric artery blood flow velocity. Arch Dis Child Fetal Neonatal Ed 85:F42-F45

36. Cory JG 1992 Purine and pyrimidine nucleotide metabolism. In: Devlin TM (ed) Textbook of Biochemistry. Wiley-Liss, New York, pp 529-571

37. Granger HJ, Norris CP 1980 Role of adenosine in local control of intestinal circulation in the dog. Circ Res 46:764-770

38. Sawmiller DR, Chou CC 1988 Adenosine plays a role in food-induced jejunal hyperemia. Am J Physiol 255:G168-G174

39. Sawmiller DR, Chou CC 1990 Jejunal adenosine increases during food-induced jejunal hyperemia. Am J Physiol 258:G370-G376
40. Sawmiller DR, Chou CC 1992 Role of adenosine in postprandial and reactive hyperemia in canine jejunum. Am J Physiol 263:G487-G493

41. Granger DN, Valleau JD, Parker RE, Lane RS, Taylor AE 1978 Effects of adenosine on intestinal hemodynamics, oxygen delivery, and capillary fluid exchange. Am J Physiol 235:H707-H719

42. Berne RM, Knabb RM, Ely SW, Rubio R 1983 Adenosine in the local regulation of blood flow: a brief overview. Fed Proc 42:3136-3142

43. Buxton DB, Fisher RA, Robertson SM, Olson MS 1987 Stimulation of glycogenolysis and vasoconstriction by adenosine and adenosine analogues in the perfused rat liver. Biochem J 248:35-41

44. Wallus KM, Fondacaro JD, Jacobson ED 1981 Effects of adenosine and its derivatives on the canine intestinal vasculature. Gastroenterology 81:327-334

45. Sawmiller DR, Chou CC 1991 Adenosine is a vasodilator in the intestinal mucosa. Am J Physiol 261:G9-G15

46. Bustamante SA, Sanches N, Crosier J, Miranda D, Colombo G, Miller MJS 1994 Dietary nucleotides: effects on the gastrointestinal system in swine. J Nutr 124:149S-156S

47. Kolassa N, Stengg R, Turnheim K 1977 Adenosine uptake by the isolated epithelium and guinea pig jejunum. Can J Physiol Pharmacol 55:1033-1038

48. Sonoda T, Tatibana M 1978 Metabolic rate of pyrimidines and purines in dietary nucleic acids ingested by mice. Biochim Biophys Acta 521:55-66

49. Uauy R 1989 Dietary nucleotides and requirements in early life. In: Lebenthal E (ed) Textbook of Gastroenterology and Nutrition in Infancy. Raven Press, New York, pp 265-280

50. Ho CY, Miller KV, Saviano DA, Crane RT, Ericson KA, Clifford AJ 1979 Absorption and metabolism of orally administered purines in fed and fasted fats. J Nutr 109:1377-1382

51. Salati LM, Gross CJ, Henderson LM, Saviano DA 1984 Absorption and metabolism of adenine, adenosine-5'-mono-phosphate, adenosine and hypoxanthine by the isolated vascularly perfused rat small intestine. J Nutr 114:753-760

52. Parsons DS, Shaw MI 1983 Use of high performance liquid chromatography to study absorption and metabolism of purines by rat jejunum in vitro. Q J Exp Physiol 68:53-67 